\title{
Sustainable transitions towards a resilient and decentralised future: Japan's Circulating and Ecological Sphere (CES)
}

\author{
Fernando Ortiz-Moya ${ }^{1}\left[\right.$ - Yatsuka Kataoka ${ }^{1} \cdot$ Osamu Saito ${ }^{1,2} \cdot$ Bijon Kumer Mitra ${ }^{1} \cdot$ Kazuhiko Takeuchi $^{1,2}$
}

Received: 16 August 2020 / Accepted: 15 March 2021 / Published online: 31 March 2021

(c) The Author(s) 2021, corrected publication 2021

\begin{abstract}
Global environmental change, the depletion of natural resources, and unacceptable levels of pollution, among other anthropogenic impacts on the planet and its ecosystems, demand a radical shift in the way humankind develops. Global agreements like the "2030 Agenda for Sustainable Development" or the "Paris Agreement on Climate Change" seek to promote sustainable development and its integration in policymaking. Against this backdrop, the Government of Japan in its Fifth Basic Environment Plan of 2018 proposed the concept of the Circulating and Ecological Sphere (CES) to guide sustainable transitions in light of the sustainable development goals (SDGs). The CES provides a framework for a new paradigm in sustainable development bringing together existing approaches, namely, rural-urban linkages, ecosystem-based solutions, decarbonisation, and resource circulation. Still in an embryonic stage, some regional and local authorities in Japan have started to experiment with ways to apply this concept on the ground. Drawing on a systematic literature review on the different components covered by the CES, along with analysis of a case study in Suzu, Japan, this paper explores how this new concept can contribute to achieve a sustainable future.
\end{abstract}

Keywords Circulating and Ecological Sphere $\cdot$ Sustainable development goals · Ecosystem-based solutions ·

Decarbonisation $\cdot$ Resource circulation $\cdot$ Rural-urban linkages

\section{Introduction}

Sustainable development has emerged as one of the most critical issues of the twenty-first century. Over the last 200 years, human activities have increased their impact on earth-depleting resources, augmenting toxic emissions, polluting land, air, and water-threatening the existence of many planetary life support systems and exceeding the planet's carrying capacity (Brundtland 1987; Mebratu 1998; Steffen et al. 2015). The consequences will be suffered by everybody, but more so by the poorer sections of society as environmental degradation and climate change threatens

Handled by Tobias Plieninger, Georg-August-Universitat Gottingen, Germany.

Fernando Ortiz-Moya

ortiz-moya@iges.or.jp

1 Institute for Global Environmental Strategies, 2108-11, Kamiyamaguchi, Hayama, Kanagawa 240-0115, Japan

2 Institute for Future Initiatives, The University of Tokyo, 7-3-1 Hongo, Bunkyo-ku, Tokyo 113-0033, Japan their livelihoods and might push them back into poverty (Munang et al. 2014). There is an urgent need to find an alternative development paradigm that balances the coupled human and natural systems without sacrificing one or another (Elmsquist et al. 2018).

The salience of this challenge has prompted governments at every level, researchers, and civil society to explore novel ways to sustain development while limiting the pressure human activities put on Earth. The global community came together in 2015 to adopt three milestone agreements to accelerate the integration of sustainable development considerations into policy and to ensure that society grows more resilient to disasters and to climate change. Together, the "Sendai Framework for Disaster Risk Reduction", the "2030 Agenda for Sustainable Development", and the "Paris Agreement on Climate Change", reinforce the idea that to tackle the global challenges ahead, it is vital to recognise the interdependencies and interconnections between social, economic, and environmental concerns and address them simultaneously. Moreover, regardless of their universal character, challenges are also place-based and depend on the distinctive socioeconomic and ecological attributes of each region both 
in the way they unfold and in discovering the best possible solutions (Kates et al. 2001; Clark and Dickson 2003).

The logical conclusion from the above is that policies advancing sustainable development need to be all-encompassing in their scope while simultaneously catering to the local context. Against this background, in 2018, the Ministry of the Environment, Japan adopted its Fifth Basic Environment Plan, the country's first statutory plan in accordance to the SDGs and which embodied an integrated approach to environmental, economic, and social issues (Takeuchi and Yamada 2018). To guide the implementation of the SDGs in a concrete way, the plan proposed the concept of the Circulating and Ecological Sphere (CES; chiiki junkan kyõsei$k e n$ in Japanese). The CES advances a spatio-environmental system in which "each region demonstrates its strengths by utilizing its unique characteristics, thereby building a selfreliant and decentralized society where different resources are circulated within each region, leading to symbiosis and exchange with neighbouring regions according to the unique characteristics of each region" (MOEJ 2018, pp 27-28).

The CES integrates responses to climate change, biodiversity loss, and the advancement of the SDGs by combining recurrent 'niches' in sustainability science-such as rural-urban linkages, the circular economy, transitions to low or zero-carbon living, or ecosystem-based solutions to disaster risk reduction and climate change adaptation and mitigation. It works as an umbrella concept that unlocks latent synergies between those niches but differs from other such frameworks in that the CES emphasises spatial considerations. It acknowledges regional heterogeneity and its embeddedness within a concrete socioeconomic context in which regions make full use of their potential as well as collaborating with each other. At its core, the CES proposes the establishment of new rural-urban linkages allowing for a more ecological circulation of natural and socioeconomic resources as the basis for implementing other core approaches to sustainable development. Ultimately, it brings the much needed critical reflection to unite different sustainable transition pathways and maximise their benefits (Luederitz et al. 2017).

This paper advances the current understanding of the CES, framing it within wider intellectual antecedents and lineages in sustainability science, showing its practical application in Suzu City, Japan. Relatively isolated from any major urban area, Suzu is a small municipality facing severe structural issues, ranging from extreme population ageing to the loss of economic activities or financial difficulties to guarantee the provision of public services-problems that are shared by many other small-sized municipalities worldwide. This case is relevant to advance the study of the CES in that it presents a locality striving to reframe its strategies from a sustainable standpoint. This case complements recent research on the subject focusing on distinct national contexts-for example on Nagpur City, India (Thapa et al. 2020).

The paper first defines the CES concept. Then, it goes on to review the literature on the four approaches covered under the CES umbrella-i.e., rural-urban linkages, ecosystembased solutions for climate change adaptation and mitigation, decarbonisation based on the use of renewable energy, and resource circulation. The paper continues by exploring the case of Suzu, Japan, which shows how the CES advances sustainable development policymaking that is tailored to the local context while helping to overcome a place's own limitations. Finally, it concludes with recommendations for further research to aid the work of policymakers implementing this novel idea.

\section{The Circulating and Ecological Sphere (CES)}

In the wake of the 2030 Agenda for Sustainable Development, the Ministry of Environment of Japan approved the Fifth Basic Environment Plan in 2018. It places two main ideas at the centre of the country's sustainable development policies: the need to respect planetary boundaries and the urgency to attain the SDGs (Takeuchi and Yamada 2018). To face the intricacy and scope of this task, the plan proposes the Circulating and Ecological Sphere (CES) as a new concept to articulate sustainable transitions. Conceptually, the CES creates a safe operation space for human development premised on multi-layered circular regions connected by the supply and demand of ecosystem services.

This concept is built upon the idea that sustainable society is envisioned as three societies-i.e., low-carbon society, circular society, and society living in harmony with nature-that was proposed in the 'Becoming a Leading Environmental Nation in the 21st Century-Japan's Strategy for a Sustainable Society" (21 seiki kankyo rikkoku senryaku in Japanese) in 2007. Together, the three societies were to answer to the environmental crises of global warming, increased waste, and the destruction of natural ecosystems and biodiversity (MOEJ 2007). Since 2007, this idea informed Japan's environmental strategies with different iterations to meet the challenges of particular problems. Ever since, consecutive national guidelines for environmental policy have striven to integrate the visions underlying the three societies (Hotta 2011). The advent of the SDGs in 2015 implied a strong sense of urgency for devising strategies solving multiple issues in a cohesive manner that considers the three dimensions of sustainable developmenti.e., economic, social, and environmental. With this in mind, the CES creates a framework to foster the interaction and cooperation of the three visions for society outlined in 2007.

In responding to Japan's context, the CES speaks to two pressing challenges facing the country. First, the progressing 
depopulation of the country and in particular, of rural spaces (Masuda 2014). This problem already affects other countries-and will reach many others in the future-but, if well managed, it might open opportunities for advancing sustainable development (Jarzebski et al. 2021 in press; Matanle and Sáez-Pérez 2019; Ortiz-Moya 2020). Second, the CES also reflects a re-evaluation of Japanese society's relationship with nature following the Fukushima Daiichi nuclear power plant disaster on 11 March 2011 (Takeuchi et al. 2014). The accident raised concerns about the safety of nuclear energy and created a sense of urgency for many municipalities to explore ways to locally produce renewable energy to meet their own needs and increase their selfsufficiency and resilience to disasters.

The definition of the CES adopted in this paper places spatial considerations at the forefront. It implies the importance not only of thinking carefully about what kind of anthropogenic activities there are and how they happen, but also where they happen and their spatial relations. The CES redesigns the territorial dimension of human activities to optimise their range of action, emphatically putting forward a self-reliant and decentralised society. It starts from the local scale, inviting communities to use their available resources and assess their own capacity to live in harmony with nature via reducing waste, generating renewable energy, and utilising ecosystem services without damaging them. It then scales up to render new value chains, complementing local resources, organically tying communities and regions together supporting each other. Ultimately, this new way of thinking optimises the scale at which different human activities happen, thereby minimising their impact on the environment.

This system results in a new spatial network in which intra- and inter-regional synergies are based on the exchange of materials, energy, and financial and human resources. For instance, employing biomass in heating systems or wind in energy production will not only decrease waste, greenhouse gas (GHG) emissions, and fossil fuel dependency but will also contribute to socioeconomic benefits such as the creation of local employment and resilience to disasters through securing energy. Instead of creating an autarkic system, as localities grow self-reliant, they will also need to partner with others to meet their own needs. Exchanges between rural and urban areas, between different regions, and across national borders will render a new human settlement system in which its different parts are connected by natural resources. Nevertheless, if this new settlement system is to function well, it might require the conception of more equitable and multi-level governance systems, affordable practices, and public-private partnerships, among other tools and solutions, ensuring all-round facilitation for the circulation of resources (Kozar et al. 2019).
To guide the formation of this system, the CES brings together concepts already familiar in sustainable development-e.g., rural-urban linkages, the circular economy, transitions to a low-carbon society, or ecosystem-based solutions. They have focused on particular aspects of the production and consumption process but without explicitly questioning the territorial and scalar dimensions of those activities, either considering cities, the countryside, or natural environments but ignoring the indissoluble connection between them (MOEJ 2018; Takeuchi et al. 2019). As will be discussed below, by incorporating rural-urban linkages, and thus, emphasising spatial considerations, the CES maximises the returns of the other three concepts while restricting their externalities. Most of these schemes are also sectoral in scope insofar they address material resources, GHG emissions, or building resilience to climate change. Although the inclusion of co-benefits may be viewed as a step towards breaking this limitation, this is still insufficient to propose integrated strategies to sustainable development. The lessons learned from these four concepts converge under the CES umbrella, which in turn, holds the potential to break the silo approach to much of sustainable development policymaking.

\section{Approaches to implementing the Circulating and Ecological Sphere (CES)}

Rather than prescribing solutions, the CES inspires a new way of thinking based on unlocking synergies between wellestablished methods for advancing sustainability by stressing spatial linkages. It fosters integrated and complex responses that emanate from the local scale, contrasting with many current fragmented approaches reacting to a single perceived need. What follows explores four approaches to implementing the CES-rural-urban linkages, ecosystem-based solutions, decarbonisation, and resource circulation-which in turn, facilitate cross-cutting interventions fostering a symbiotic relationship among them (Fig. 1).

\section{Rural-urban linkages}

Space is an important aspect to consider when advancing sustainable development. Where people live and work influences environmental footprints, and therefore, the organisation of human settlement systems and the relationship among urban and rural areas will be key to confronting environmental challenges (Mani et al. 2005). Within this debate, much of the attention has focused on cities, given the additional pressure they put on the environment. For instance, in 2006, cities were responsible for $67 \%$ of the world's total energy consumption and $70 \%$ of the $\mathrm{CO}_{2}$ 
Fig. 1 Showing the relationship between the four approaches to implementing the CES. Ruralurban linkages is the central element of the CES, working as the connective tissue across the three other sustainable development perspectives

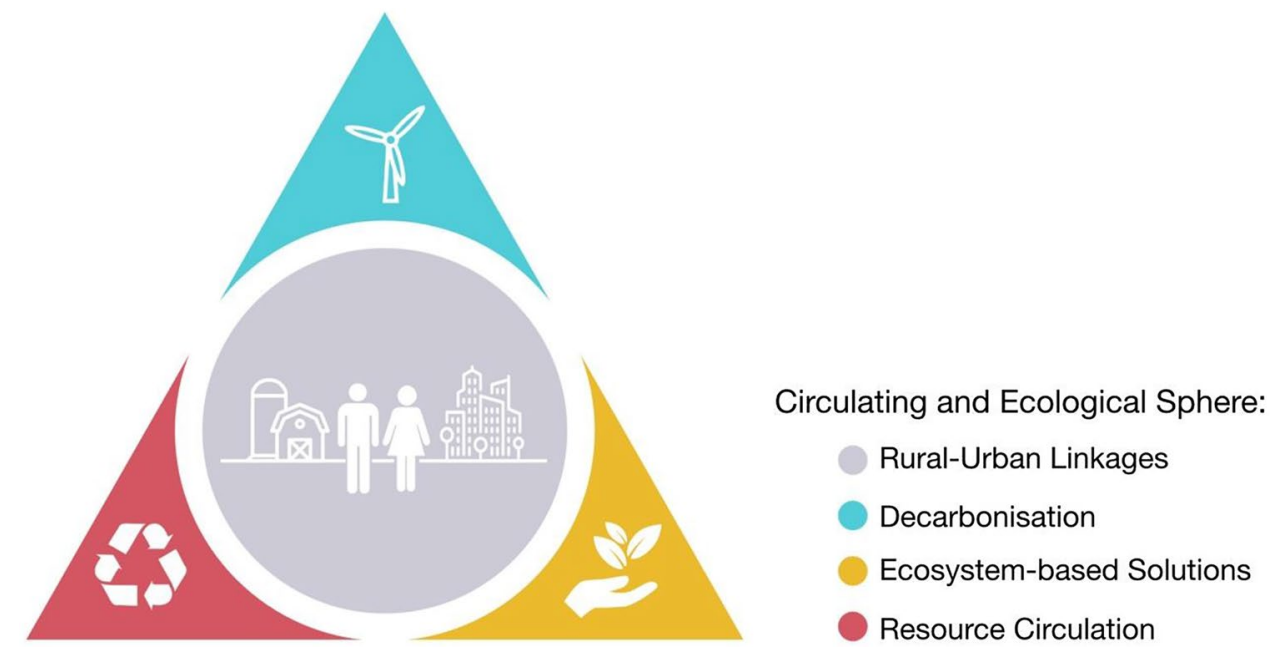

energy-related emissions (UN-HABITAT 2011). On the other side of growing urban populations, rural areas are undergoing severe ageing and depopulation, generating a host of different environmental problems stemming from the lack of human resources to manage and preserve natural spaces. Whether population concentrates further in dense urban areas, or this trend reverts and society disperses, will impact on how to catalyse sustainable transitions (Saito et al. 2019).

This discussion is still entrenched in the traditional understanding of rural and urban areas as separated entities (Hugo et al. 2003); even the most recent report of the United Nation's World Urbanisation Prospect, published in 2018, makes this division to study 233 countries (UNDESA 2019). Although each country has its own definition of 'rural' and of 'urban', in general, the rural has been defined as superfluous to the urban (Hugo et al. 2003). This rural-urban division is leading in most countries to a compartmentalised approach to policymaking, either focusing on cities or on rural areas (Caffyn and Dahlström 2005).

However, recent research has progressively broken this monolithic dichotomy (Wachsmuth 2012). This is not only because of the ever-growing flows linking cities and the countryside or the geographical fluidity of industrial classifications (Steinberg 2014), but also because of the emergence of new spatial forms that are neither urban nor rural-including different phenomena of peri-urban expansion of informal settlements in developing nations such as desakota or favelas (Firman 1996; Cairns 2018). Studies focusing on rural-urban linkages have shed light on the networked nature of human settlements that can lead to significant improvements in the environment (Woods 2009). Still, the constraints and opportunities of rural-urban connections to support sustainable development remain substantially underexplored (Akkoyunlu 2015).
Rural-urban linkages refer to the large and increasing flows happening between rural and urban areas, including but not limited to people, goods, waste, finance, or information (Tacoli 1998, 2003). Nonetheless, there is a limited understanding of what these flows, whether material or immaterial, consist of, since new ones are constantly being created (Mayer et al. 2016). In a nutshell, cities are nodes offering the following aspects to rural areas: (1) goods and services; (2) socioeconomic and cultural interactions; (3) connections to national and global infrastructure, telecommunications, and knowledge networks; and (4) public services and administration (Bellet and Llop 2004; Berdegué et al. 2015). For rural areas, cities are: (1) marketplaces for their products; (2) production and distribution centres; (3) centres for non-agricultural jobs; and (4) centres that attract rural migrants (Satterthwaite and Tacoli 2006; Berdegué et al. 2015). These aspects interlink rural and urban areas, creating a reciprocal dependency between them. A final consideration is that cities and the countryside are no longer isolated but are part of an increasingly integrated regional system-at the same time embedded in a global network of interconnected spaces allowing the mobility of people, goods, information, or resources (Marsden 2009).

A key appeal of the CES is that it encourages the creation of more complex and sustainable rural-urban linkages based on the recalibration of existing flows of food, goods, people, capital, waste, natural resources, or energy - in the form of renewable energy - amongst many others. These new linkages hold the potential to spatially recast ecological production and consumption chains to their most effective scale, whereby towns and cities meet their basic needs within their rural hinterland primarily seeking selfsufficiency for energy and food, minimising waste, and thus, growing more resilient (Takeuchi et al. 2016). This becomes the lowest level from which resource circulation 
is built in consecutively enlarging areas of influence all welded together at a variety of nested geographical scales.

\section{Ecosystem-based solutions}

Ecosystem-based solutions ${ }^{1}$ have been advocated in recent years as an integrated method to foster sustainability transitions (Wamsler 2015). They harness the innate, but often neglected, capacity of nature to address socio-environmental challenges by promoting healthy ecosystem services, understood as "the conditions and processes through which natural ecosystems, and the species that make them up, sustain and fulfil human life" (Daily 1997, p. 3). Ecosystem-based solutions represent an alternative to the customary construction of grey infrastructure based on assimilating nature into building comprehensive strategies embracing the three dimensions of sustainable development, thereby reframing how humans work with nature (Saito et al. 2019). They allow communities to anticipate and better prepare for the adverse effects of extreme events, whether natural disasters or those induced by climate change.

Ecosystem-based solutions are cross-cutting and costeffective, yielding ample advantages to the areas implementing them across the three dimensions of sustainable development (Munang et al. 2013). They can be deployed in urban and rural areas alike. Research on the topic aims at exploring the possible benefits resulting from implementing such solutions. The socioeconomic benefits, especially in regards to vulnerable populations, include income gains and more secure livelihoods, enhancement of social cohesion, gender inclusion, community empowerment, improved health conditions, better food and water security, as well as reduced restoration costs after climate-related damage (Doswald et al. 2014). Environmental benefits consist of, among others, carbon sequestration, reduced land degradation and erosion, improved air quality, the restoration of habitats and ecosystems, protection of biodiversity, and fewer ill-effects from micro-climatic changes (Munang et al. 2013; Doswald et al. 2014).

The challenge remains to better integrate ecosystembased solutions into policy and to overcome perceived barriers. As UNEP (2011) noted, one of the dangers is the idea that ecosystem-based solutions "are not valued within the current economic model" (p. 3). Ershad Sarabi et al. (2019) identified six reasons as the main factors impeding their

\footnotetext{
${ }^{1}$ For the purpose of this paper, the term ecosystem-based solution encompasses notions which although are studied separately, share more in common than not, including: Nature-Based Solutions (NBS); Ecosystem-based Disaster Risk Reduction (Eco-DRR); Ecosystem-based Adaptation (EbA); Natural Water Retention Measures (NWRM), or Green Infrastructure (Faivre et al. 2018).
}

uptake, including: (1) "inadequate financial resources;" (2) "path dependency;" (3) "institutional fragmentation;" (4) "inadequate regulations;" (5) "limited land and time availability;" and (6) "uncertainty regarding implementation process and effectiveness of the solutions" (p. 8). Therefore, it is paramount to increase research efforts to demonstrate the effectiveness of ecosystem-based solutions and compare them to technology-based ones, while also creating a reference collection of best-practices (Faivre et al. 2018).

Projects deploying ecosystem-based solutions depend largely on including local communities into the planning and implementation stages to guarantee their success (Munang et al. 2014). Another important aspect would be to integrate local knowledge into ecosystem-based solutions to address the limited understanding among policymakers (Saito 2017). Examples of this already exist, such as Japan's Satoyama and Satoumi areas. Satoyama denotes those natural areas at the outskirts of cities, towns, or villages shaped by human activities, like agriculture, which are rich in biodiversity, while Satoumi refers in particular to marine and coastal ecosystems. Satoyama and Satoumi help to preserve ecosystems and their services, simultaneously providing for the wellbeing of humans (Takeuchi et al. 2016).

The CES takes after ecosystem-based solutions in rebuilding human-nature relations by decoupling economic development from its pernicious effects on the environment, as has been exemplified by Satoyama and Satoumi landscapes (Takeuchi 2010). Both approaches work at multiple levels, emanating from the local and creating synergic relationships between different regions as they scale up in increasing resilience against disasters and the impacts of climate change.

\section{Decarbonisation}

Currently, one of the most discussed topics in sustainable development is how to achieve carbon neutrality-i.e., zero GHG emissions. There is not a one-size-fits-all model for decarbonisation. Each plan needs to be tailored to the specific socio-political context, economic power, and stage of development. Reducing emissions will depend on the performance of different sectors, including residential, industrial, commercial, passenger and freight transport, and electricity generation; this will be also influenced by aspects such as technological innovation, the use of renewable energy, changes in lifestyles, urban morphology and land use, or transport modal shift to name but a few (Gomi et al. 2007; Shimada et al. 2007). Differences aside, the one common denominator among low-carbon development models is the importance given to climate-compatible energy sources and energy efficiency (Skea and Nishioka 2008). 
Since the industrial revolution, economic development has been strongly interconnected to increasing energy use, and thus, to growing GHG emissions and all sorts of other environmental problems (IPCC 2011). As more countries reach higher levels of development, their energy needs also increase, adding an extra burden on the environment. Renewable energy systems - those that make use of nature such as wind, tides, geothermal heat, biomass, or sunlightare fundamental to achieve sustainable development and the decoupling of economic growth from environmental damage.

Regardless of uninterrupted technological advancement and lower costs in producing renewable energy, non-renewable energy still dominates the energy mix of most countries (Lechtenböhmer et al. 2016). Studies have explored the barriers impeding the adoption of renewable energy at the national level, both in developed and developing countries such as the United States (Sovacool 2009), Australia (Byrnes et al. 2013), India (Luthra et al. 2015), or Trinidad and Tobago (Khan and Khan 2017). Despite the different contexts, the barriers are shown to be fairly similar; they include institutional, financial and economic, technical, and sociocultural, with studies focusing on developing countries also noting legislative and capacity barriers. General recommendations to overcome this array of barriers usually focus on giving (mostly economic) incentives.

To decarbonise worldwide energy systems will require more than economic incentives-it will mean an in-depth reconfiguration not only of technological and infrastructural aspects, but also of social and cultural practices in a spatial context. The shift to a low-carbon energy grid goes beyond phasing out the current carbon-intensive energy infrastructure. More recently, and in light of the reinvigorated 'spatial turn' of energy research, scholars are exploring the geographical dimension of the transition to renewable energy (Calvert 2016). As Bridge et al. (2013) points out, "the lowcarbon energy transition is fundamentally a geographical process that involves reconfiguring current spatial patterns of economic and social activity" (Bridge et al. 2013, p. 331).

By looking to energy systems through a geographical lens, exploring where energy is produced and consumed and what it is used for, a more nuanced understanding has begun to emerge of the optimal pathway to transition to a lowcarbon society. In turn, unpacking the geographical character of energy transitions has significant policy implications (Bridge 2018). First, a low-carbon conversion might result in spatially uneven development and growing inequalities (Balta-Ozkan et al. 2015). Second, the spatial configuration of the network and the multiple scales at which renewable energies can be deployed, from micro to macro, expands the number of possible scenarios for achieving a low-carbon energy system (Walker and Cass 2007). Third, this shift will unleash processes of creative destruction as the current carbon intensive network-with its territorially well-embedded paths, practices, and infrastructures-is dismantled while new climate-conscious ones are created (Lovio et al. 2011). Finally, this spatial turn indicates that to achieve a $100 \%$ renewable energy grid will entail an "increased decentralisation of energy production and consumption" (Bagliani et al., 2010, p. 458).

The CES invites local areas to explore their untapped potential for renewable energy sources, subsequently creating a more flexible and decentralised grid built upon new intra- and inter-regional linkages based on energy. Rural areas can benefit from their (mostly unexploited) renewable energy resources-wind, hydro, or solar-for their own consumption as well as for exchanging the surplus energy with other nearby areas or cities for other commodities (Aiken 2012).

\section{Resource circulation}

The Circular Economy (CE) has emerged as a framework to drastically reconceptualise current production and consumption processes, encouraging the preservation rather than the exhaustion of Earth's natural resources, most of which are finite in character (Korhonen et al. 2018). CE aims at closing the loop of the production lifecycle minimising the use of raw resources and the production of waste (EMAF 2015). Instead of the current linear process-in which natural resources are extracted, transformed into goods, consumed, and finally disposed-CE proposes a model in which once products are used and no longer needed, they can be recycled or reused, thus bringing materials back into the production/consumption cycle and effectively turning waste into a resource (EMAF 2015). In an ideal CE system, only biodegradable materials are expelled outside this cycle to the biosphere, while non-biodegradable materials remain circulating for as long as possible-reducing the impact of human activities on the planet and slowing down the current pace of resource depletion (Wijkman and Skanberg 2015).

CE has been rapidly embraced by governments at every level-including the European Union and some of its member states, the UK, China, and Japan—usually justifying its adoption due to expected impacts on the job market and the economy (COM 2014). However, evidence shows a limited level of implementation so far, resulting from existing system barriers that hinder progress towards its realisation. Kirchherr et al. (2018) have analysed some of the current barriers in the European Union. Based on 47 interviews with business owners, academics, and policymakers, they identify four main types of barriers to achieving a CE: market, regulatory, technological, and cultural. Their findings contrast with the widespread assumption that technology is the most significant aspect slowing down progress (Mont et al. 
2017); instead, they suggest that cultural barriers, and more especially "lack of consumer interest and awareness" and "hesitant company culture" (Kirchherr et al., 2018, p. 270) are two of the challenges facing the mainstreaming of CE in Europe. This reveals the urgent need to bridge the gap between theoretical understandings of $\mathrm{CE}$ and its practical implementation.

Besides system barriers, there remain other aspects that, if not further explored, might limit the positive effects of CE or even undermine them. Korhonen et al. (2018) acknowledged six main limitations challenging the contribution of $\mathrm{CE}$ to environmental sustainability such as "those concerning thermodynamics, definition of CE system boundaries and challenges in the governance and management of the CE-type interorganizational and inter-sectoral material and energy flows" (p. 45). One surprising element is the CE's current omission of spatial system boundaries, which in an increasing globalised world-where production and consumption happen, more often than not, at great distance-might bring into question its total net sustainability. The flows of raw materials, finished goods, waste, and pollution all disregard administrative boundaries, and this needs to be considered when designing CE policies. On this subject, Mattila et al. (2010) showed that the biggest environmental impacts of a successful recycling industrial park took place outside its system boundary in other areas of its supply chain. Research should therefore look at the regional and global scales of CE systems to minimise the possible trade-offs undermining the CE's capacity to advance sustainable transitions.

Another aspect needing further research is how to better integrate the built environment into a CE. For example, few studies or practical examples have considered the construction sector, despite this being one of the largest consumers of raw materials and accounting for $25-40 \%$ of global $\mathrm{CO}_{2}$ emissions (Pomponi and Moncaster 2017). Others have referred to the shortcomings of applying CE to cities, in sharp contrast with local governments' attempts at making their cities circular. Arguments reiterate the lack of consideration for the physical quality of cities and in particular of their land and their infrastructure systems. However, these two elements are essential to develop ecosystem services aiding the regenerative capacity of cities, to optimise the way resources are used and circulated within the territory, and the relationship of cities and their hinterland (Williams 2019).

In acknowledging the significance of fostering selfsufficient regional ecological processes, the CES advances circular systems at the regional scale that spatialise the principles of the circular economy. Although within the current global capitalist system it seems impossible to localise all resource flows, realistically, more of these flows could be localised. The CES invites a rethink of spatial boundaries guiding the territorialisation of the circulation of resources by encouraging municipalities to ponder which of their needs can be met locally and regionally as well as by putting systems in place to increase the reuse and recycling of waste.

\section{Applying the CES framework in Suzu City, Japan}

The case of Suzu City, Japan, illustrates how municipalities can reconsider their policies based on the CES from an integrative standpoint that makes the best use of the local underused natural and human resources. Suzu is a small municipality situated at the tip of the Noto Peninsula, Ishikawa Prefecture (Fig. 2). Although officially designated as a city, it resembles a rural town, due to its dispersed settlement pattern, predominantly agricultural economy, and small population. More than $70 \%$ of its land is covered by forests, which together with its coastal area, offer plenty natural resources that the town can rely on. Its remote location and unique orography, its relative isolation from other towns or big urban centres, and its limited economic opportunities exacerbated the exodus of youth to more prosperous, and mostly urban, areas, as they sought better education and job opportunities. Suzu's population peaked at 38,157 in 1950 and had decreased by $61 \%$ to a total of 14,625 in $2015 .^{2}$

Up until recently, the city was implementing a wide range of plans to curb outmigration and revitalise its economy, all similar to those of other Japanese shrinking municipalities, such as providing child-rearing support or measures to help newcomers taking over traditional industries-unfortunately, without yielding the desired outcomes. With more than $47 \%$ of its inhabitants aged 65 years and older, Suzu's migration trends and demographic profile put it "at risk of vanishing." ${ }^{\text {"I }}$ In 2016, the city launched the 'Population Vision for Suzu City' with the objective of stabilising its population at 10,000 by 2040 , subsequently lowered in the 2020 revision to 9500 inhabitants, ${ }^{4}$ and increasing the number of working age population in the 20 to 30 year-old cohort as a means to guarantee the region's vitality (Suzu City 2020a).

In light of this challenge, it is essential to have a guiding framework when envisioning interventions in decaying rural communities from a sustainable standpoint that helps to coordinate existing policies while also exploring new possibilities based on local assets. In planning for a future with fewer people, Suzu has shifted its approach to development

\footnotetext{
${ }^{2}$ Population data from Japan national census, available online at: e-stat.go.jp.

3 This is noted by the city itself in the SDG Future City Masterplan (Suzu City 2018, p. 2).

4 This still surpasses Japan's official projection of 7,200.
} 


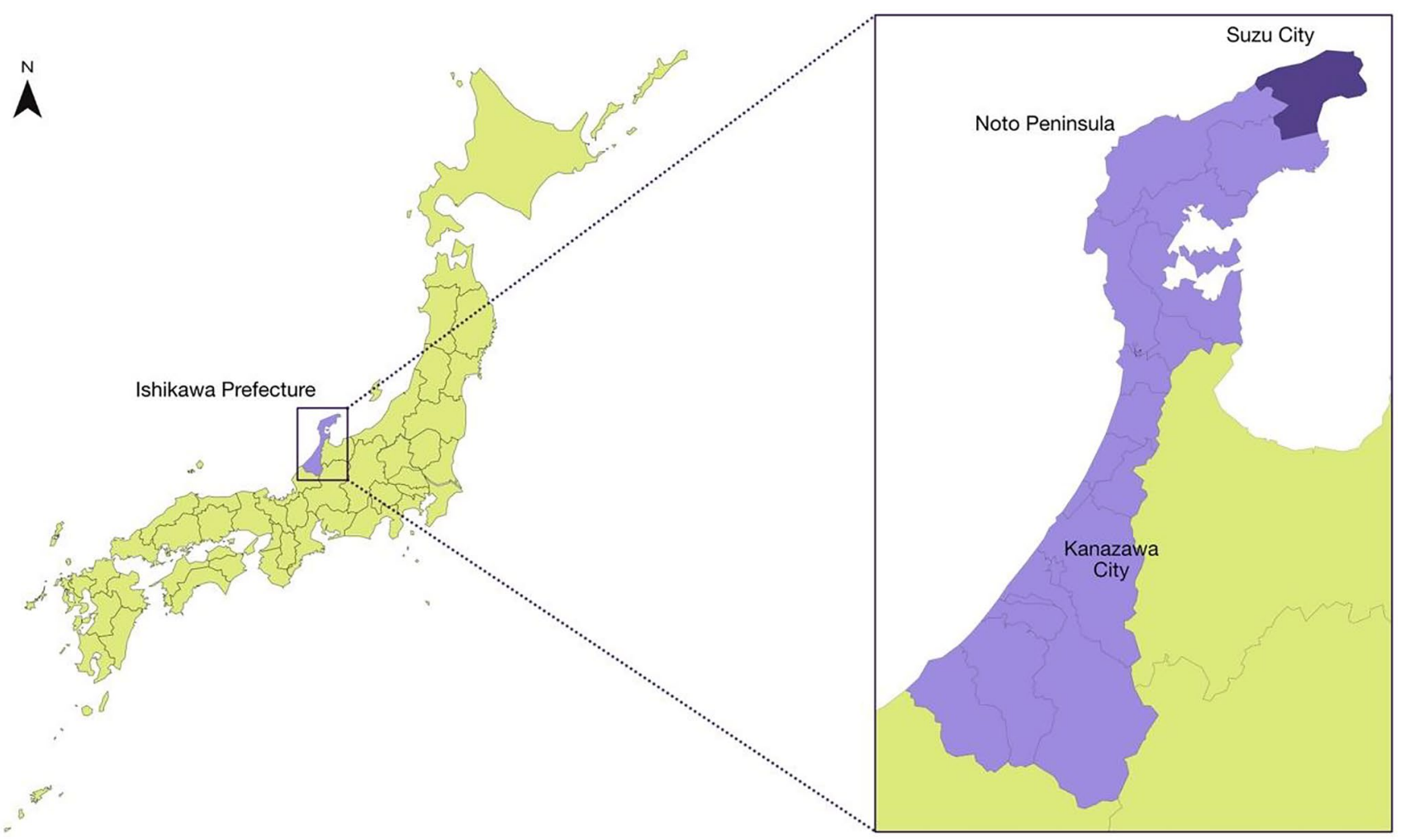

Fig. 2 Location of Suzu City

to promote sustainable principles. This new attitude materialised in its 2018 application to become a SDGs Future City - a programme launched by the SDGs Promotion Headquarters at the Prime Minister's Office of the Government of Japan to recognise the efforts of cities working to localise the SDGs in coordination with local stakeholders. ${ }^{5}$ Suzu's proposal assesses its weaknesses and strengths, exploring ways to turn to advantage the natural and human capital latent in depopulated areas that has been ignored so far. Suzu uses the CES as a framework to integrate the three dimensions of sustainable development into the city's ordinances, nourishing synergies between existing initiatives to stimulate the vitality of the city and its regions while protecting nature (Suzu City 2018).

Given its vast natural resources, Suzu City is centering its strategy in ecosystem-based solutions to reorganise its spatial networking of economic and knowledge linkages within and outside the region. It does so by resorting to its Satoyama and Satoumi landscapes as the common thread that integrates rural-urban linkages, renewable energy, and resource circulation into a holistic scheme to galvanise supplementary

\footnotetext{
${ }^{5}$ Complete information can be found on the Promotion Office's official website https://www.kantei.go.jp/jp/singi/tiiki/kankyo/ and on the FutureCity initiative website: http://future-city.go.jp/
}

productive activities, start-up businesses, and to create new added value activities.

Suzu's rich mosaic of Satoyama and Satoumi are characterised by a holistic approach to the farming, forestry, and fishery industries in which agricultural systems are linked to mountains, forests, and the sea. The lack of large rivers in the area resulted in many human-made water reservoirs that are now the habitat of an enormous agricultural and associated biodiversity, including many endangered plants and animals. Suzu's Satoyama and Satoumi comprise traditional knowledge, resource management and agricultural techniques, religious practices, or lifestyles unique to the Noto peninsula; for instance, the Agehama-style method of salt production, the sumiyaki charcoal making technique, or the unique harvest festival Aenokoto, ${ }^{6}$ all dating back centuries. In 2011, Noto's socio-ecological production managed system was recognised by the Food and Agriculture Organization of the United Nations (FAO) as Globally Important Agricultural Heritage Systems (GIAHS).

\footnotetext{
6 The Oku-noto no Aenoko was inscribed in 2009 in UNESCO representative list of Intangible Cultural Heritage of Humanity. For more information, visit: https://ich.unesco.org/en/RL/oku-noto-no-aenok oto-00271
} 
Well-managed Satoyama and Satoumi not only preserve the distinctive biodiversity of Noto but also support the livelihoods of the local community and build resilience to climate change and other adverse events. However, depopulation threatens their survival. As the agricultural activities supporting the surrounding ecosystems fade away due to insufficient human resources, those spaces deteriorate and their centenary knowledge systems and traditions disappear (Hashimoto et al. 2019). A long-standing premise of Suzu's strategy has been to nurture its current and future human capital envisaging a city where people can lead fulfilling lives (Suzu City 2018).

To catalyse this shift, Suzu has actively engaged in creating rural-urban knowledge flows to solve some of its weak points by partnering with out-of-town research institutes. In 2006, Kanazawa University in cooperation with Suzu City opened a research and education facility reusing a building from a closed elementary school. The "Noto School" is an education hub to conserve the peninsula's biological and cultural characteristics whilst supporting entrepreneurs venturing into new productive activities. One year later, it launched the 'Noto Satoyama-Satoumi Meister Programme' for working adults under the age of 45 to develop practical skills required to make local industries more competitive and add value to the region's primary products (Nakamura and Kitamura 2018). In this programme, and subsequent iterations, professors and experts from leading organisations across Japan come to Suzu to conduct teaching activities in subjects such as farming and entrepreneurship, sustainable tourism, fishing industries, and health and welfare. ${ }^{8}$

Following Suzu's selection as a SDGs Future City, the Noto School established the 'Noto SDGs Lab', which aims at becoming a one-stop window for regional revitalisation strategies in line with the SDGs. Noto SDGs Lab will coordinate the activities of the school's graduates and match them with appropriate companies to support their new enterprises (Suzu City 2018). These activities are set to revitalise the local economy and augment urban-to-rural migration flows to buttress Suzu's demographic profile; around half of the people joining the programme are from outside the city (Nakamura and Kitamura 2018). The success of the Meister programme in training human resources prompted international partnerships with other GIAHS designated areas experiencing similar problems, and in particular, with the Ifugao province of the Philippines.

\footnotetext{
$\overline{7}$ It also houses an international state-of-the-art Atmospheric Environment Research Centre to monitor air quality. More information is available at the centre's own webpage, available at: http://k-inet.w3. kanazawa-u.ac.jp/inet/jp/co_facilities/noto.html

${ }^{8}$ Complete information is available in the programme's website: https://www.crc.kanazawa-u.ac.jp/meister/
}

Altogether, Suzu has created a multilevel network centred on its Satoyama and Satoumi comprising actions at the local, regional, and global levels, further advancing sustainability solutions (Kozar et al. 2019). This multilevel network has been instrumental in solidifying the city's efforts to implement the CES by creating partnerships with external actors-such as academia, higher levels of government, or other cities-to overcome the city's shortcomings.

Suzu has also incorporated into its strategies the achievement of a low-carbon society. The Noto Peninsula exhibits great potential to generate renewable energy, which in turn can result in additional rural-urban linkages based on the exchange of energy and financial resources. Japan Wind Development Co., Ltd opened a windmill power station in 2007 comprising of 10 units with a total power generation capacity of $15,000 \mathrm{~kW}$; this was followed by 20 additional units and 30,000 kW. ${ }^{9}$ Hokuriku Electric Power Company, together with Suzu City, opened a mega-solar power plant in 2012 with a power generation capacity of $1000 \mathrm{~kW}$. The city can meet its own energy demands through locally produced renewable energy while also selling electricity to Hokuriku Electric Power Company, which distributes it to the Hokuriku region. ${ }^{10}$

To foster a resource-circulating society that transforms waste into an useful resource,Suzu launched in 2010 the 'Suzu City Biomass Town Plan' (Suzu City 2010). The city utilises different biomass resources from the unavoidable waste of its main industries-woody biomass, livestock biomass, and fishery processing residues-food waste, and sewage sludge to produce refuse-derived fuel (RDF) and organic fertiliser, which is then used in local farms. This initiative entails the active participation of citizens to effectively collect food waste from households and restaurant facilities through a special collection system. As a form of incentive, citizens gain eco-points that can be exchanged for environmental-friendly 'made in Suzu' products in local shops participating in the programme. ${ }^{11}$ This method also promotes a sense of ownership among the local community while supporting local companies and increasing job opportunities. Moreover, the biomass plan contributes to reducing the city's carbon footprint by not incinerating waste and by creating alternatives to fossil fuels in the form of RDF.

In redefining its development model, Suzu is questioning the validity of the traditional metrics used to measure the

\footnotetext{
${ }^{9}$ All information can be obtained in its webpage: https://www.jwd. co.jp

${ }^{10}$ As highlighted by Suzu's Mayor himself in a 2018 interview, available at: https://sus-cso.com/kiji/interview-suzu-e

11 The eco-points programme includes other activities such as coast or river cleaning activities. For a full description of the programme visit: https://www.city.suzu.lg.jp/kikakuzaisei/nature_point.html (in Japanese)
} 
success or failure of cities and their policies-entrenched in a pro-growth narrative that understands population and economic growth as normative and regards any other outcome as a failure (Molotch 1993). Suzu has created its own 'Happiness Index' to measures the wellbeing of its residents and to assess the long-term impact of its policies (Tanaka et al. 2014; Qiu and Bixia 2016; Suzu City 2020b). Rather than expanding economic indicators and using this as the metric against to which measure the success of its policies, Suzu understands success as a function of increasing the wellbeing of its citizens-hence opening avenues to rethink how to measure sustainable development.

The case of Suzu provides lessons for other places looking to reconsider their transitions to sustainable development pathways, even in other socioeconomic contexts. First, it illustrates how the CES is progressively implemented and expanded. Suzu began by examining its strengths, with early initiatives focusing on its Satoyama and Satoumi, and subsequently scaled up its ambitions to cover other approaches to the CES. For instance, initiatives to preserve Suzu's Satoyama and Satoumi landscapes gave way to the Meister Programme, which culminated in the Noto SDGs Lab; this progression ushered in new rural-urban linkages, like the collaboration with Kanazawa University. Second, Suzu clarifies how to think about the optimal scale for the circulation of different resources, both material and immaterial. Natural resources and waste processing circulates at the local level, while energy and knowledge linkages expand their scale across regional, national, and international geographies supported by multilevel partnerships. Ultimately, the CES invites localities to redefine the range of action of different human activities to minimise their impact on the environment while supporting the sustainable development of society. Therefore, the CES can help cities to forge their own path to sustainability.

\section{Conclusion}

As efforts to achieve a sustainable future continue, it is fundamental to remember the complexities of the interplay between social, economic, cultural, political, technological, and ecological systems. The CES takes this complexity as the starting point to recalibrate the relationship between different pathways to sustainable development by designing new spatial linkages between rural and urban areas and between different regions. To build these flows, each locality evaluates their own dormant potential to increase their self-sufficiency-e.g., producing renewable energy or maximising the healthy use of ecosystem services-and exchange any surplus with others. This provides considerable win-win opportunities for localities and regions that, rather than damaging nature, harnesses its power to open new pathways for sustainable transitions.

This paper explores the four different approaches covered by the CES umbrella: rural-urban linkages, ecosystem-based solutions, decarbonisation, and resource circulation. In its essence, the CES fosters holistic and integrated responses to sustainable transitions in which symbioses between these four approaches appear organically. This paper illustrates practical implementation of the CES by reviewing the case of Suzu City, Japan. The CES has led Suzu to reassesses its current practices and to look within to find its dormant potential to advance a low-carbon and circular society. This process happened organically in different stages of increased scale.

The CES has tremendous potential to be a blueprint to achieve a socioeconomic model in harmony with natureas well as to reach the ambitious goals set by the Paris Agreement and the 2030 Agenda for Sustainable Development. However, there remains a number of questions requiring further research to better translate its intentions to practical interventions. First, there is the matter of scale and how to foster better cooperation between different spatial units, such intra-regional, watershed areas, with remote municipalities, or at the global level. In this regard, it is important to analyse how to identify the most appropriate scales for the circulation of different resources, and how to better mediate the circulation of each resources at the intra- and inter-regional scales. A second question is how to limit the trade-offs between achieving a low-carbon and circular society and the potential negative impacts these can have on nature-for instance the deployment of renewable energy facilities and nature conservation. Another aspect would explore the collaboration between civil society and the public sector, as well as what kind of support programmes can encourage the application of the CES. All these and other topics should be informed by theoretical and on-the-ground realities to better understand matters of scale and the complexity of the challenge to advance sustainability.

Open Access This article is licensed under a Creative Commons Attribution 4.0 International License, which permits use, sharing, adaptation, distribution and reproduction in any medium or format, as long as you give appropriate credit to the original author(s) and the source, provide a link to the Creative Commons licence, and indicate if changes were made. The images or other third party material in this article are included in the article's Creative Commons licence, unless indicated otherwise in a credit line to the material. If material is not included in the article's Creative Commons licence and your intended use is not permitted by statutory regulation or exceeds the permitted use, you will need to obtain permission directly from the copyright holder. To view a copy of this licence, visit http://creativecommons.org/licenses/by/4.0/. 


\section{References}

Aiken G (2012) Community transitions to low carbon futures in the transition towns network (TTN). Geogr Compass 6:89-99. https:// doi.org/10.1111/j.1749-8198.2011.00475.x

Akkoyunlu S (2015) The potential of rural-urban linkages for sustainable development and trade. Int J Sustain Dev World Policy 4:20-40

Bagliani M, Dansero E, Puttilli M (2010) Territory and energy sustainability: the challenge of renewable energy sources. J Environ Plan Manag 53:457-472. https://doi.org/10.1080/09640561003694336

Balta-Ozkan N, Watson T, Mocca E (2015) Spatially uneven development and low carbon transitions: insights from urban and regional planning. Energy Policy 85:500-510. https://doi.org/10.1016/j. enpol.2015.05.013

Bellet C, Llop JM (2004) Miradas a otrosespaciosurbanos: lasciudadesintermedias. Scripta Nova: RevistaElectrónica de Geografía y CienciasSociales 8:1-28

Berdegué JA, Carriazo F, Jara B et al (2015) Cities, territories, and inclusive growth: unraveling urban-rural linkages in Chile, Colombia, and Mexico. World Dev 73:56-71. https://doi.org/10. 1016/j.worlddev.2014.12.013

Bridge G (2018) The map is not the territory: a sympathetic critique of energy research's spatial turn. Energy Res SocSci 36:11-20. https://doi.org/10.1016/j.erss.2017.09.033

Bridge G, Bouzarovski S, Bradshaw M, Eyre N (2013) Geographies of energy transition: space, place and the low-carbon economy. Energy Policy 53:331-340. https://doi.org/10.1016/j.enpol. 2012.10.066

Brundtland G (1987) Our common future: the report of the world commission on environment and development. Oxford University Press, Oxford

Byrnes L, Brown C, Foster J, Wagner LD (2013) Australian renewable energy policy: barriers and challenges. Renew Energy 60:711-721. https://doi.org/10.1016/j.renene.2013.06.024

Caffyn A, Dahlström M (2005) Urban-rural interdependencies: Joining up policy in practice. Reg Stud 39:283-296. https://doi.org/ $10.1080 / 0034340050086580$

Cairns S (2018) Debilitating city-centricity: urbanization and urbanrural hybridity in Southeast Asia. In: Padawangi R (ed) Routledge handbook of urbanization in southeast Asia. Routledge, London

Calvert K (2016) From 'energy geography' to 'energy geographies': perspectives on a fertile academic borderland. Prog Hum Geogr 40:105-125. https://doi.org/10.1177/0309132514566343

Clark WC, Dickson NM (2003) Sustainability science: the emerging research program. PNAS 100:8059-8061. https://doi.org/10.1073/ pnas. 1231333100

COM (European Comission) (2014) Towards a circular economy-a zero waste progreamme for Europe. Brussels

Daily GC (1997) Nature's services: societal dependence on natural ecosystems. Island Press, Washington

Doswald N, Munroe R, Roe D et al (2014) Effectiveness of ecosystembased approaches for adaptation: review of the evidence-base. Clim Dev 6:185-201. https://doi.org/10.1080/17565529.2013. 867247

Elmsqvist T, Bai X, Frantzeskaki N et al (eds) (2018) Urban planet: knowledge towards sustainable cities. Cambridge University Press, Cambridge

EMAF (Ellen MacArthur Foundation) (2015) Growth Within. A Circular Economy Vision for a Competitive Europe, Ellen MacArthur Foundation

ErshadSarabi S, Han Q, Romme LAG et al (2019) Key enablers of and barriers to the uptake and implementation of nature-based solutions in urban settings: a review. Resources 8:121. https://doi. org/10.3390/resources 8030121

Faivre N, Sgobbi A, Happaerts S et al (2018) Translating the Sendai Framework into action: the EU approach to ecosystem-based disaster risk reduction. Int J Disaster Risk Reduct 32:4-10. https:// doi.org/10.1016/j.ijdrr.2017.12.015

Firman T (1996) Urban development in Bandung Metropolitan Region: a transformation to a Desa-Kota Region. Third World Plan Rev 18:1. https://doi.org/10.3828/twpr.18.1.t537086351458357

Gomi K, Shimada K, Matsuoka Y, Naito M (2007) Scenario study for a regional low-carbon society. Sustain Sci 2:121-131. https://doi. org/10.1007/s11625-007-0023-z

Hashimoto S, DasGupta R, Kabaya K et al (2019) Scenario analysis of land-use and ecosystem services of social-ecological landscapes: implications of alternative development pathways under declining population in the Noto Peninsula, Japan. Sustain Sci 14:53-75. https://doi.org/10.1007/s11625-018-0626-6

Hotta Y (2011) Is resource efficiency a solution for sustainability challenges? Japan's sustainable strategy and resource productivity policy in the 21st century. Surveys and Perspectives Integrating Environment and Society

Hugo G, Champion A, Lattes A (2003) Toward a new conceptualization of settlements for demography. Popul Dev Rev 29:277-297. https://doi.org/10.1111/j.1728-4457.2003.00277.x

IPCC (2011) Summary for policymakers. In: Edenhofer O, PichsMadruga R, Sokona Y et al (eds) IPCC special report on renewable energy sources and climate change mitigation. Cambridge University Press, Cambridge

Jarzebski MP, Elmqvist T, Gasparatos A et al (2021) Ageing and population decline: implications for sustainability in the urban century. Urban Sustain (in press)

Kates RW, Clark WC, Corell R et al (2001) Sustainability science. Science 292:641-642. https://doi.org/10.1126/science.1059386

Khan Z, Khan AA (2017) Current barriers to renewable energy development in Trinidad and Tobago. Strat Plan Energy Environ 36:8 23. https://doi.org/10.1080/10485236.2017.11863769

Kirchherr J, Piscicelli L, Bour R et al (2018) Barriers to the circular economy: evidence from the European Union (EU). Ecol Econ 150:264-272. https://doi.org/10.1016/j.ecolecon.2018.04.028

Korhonen J, Honkasalo A, Seppälä J (2018) Circular economy: the concept and its limitations. Ecol Econ 143:37-46. https://doi.org/ 10.1016/j.ecolecon.2017.06.041

Kozar R, Galang E, Alip A et al (2019) Multi-level networks for sustainability solutions: the case of the International Partnership for the Satoyama Initiative. CurrOpin Environ Sustain 39:123-134. https://doi.org/10.1016/j.cosust.2019.09.002

Lechtenböhmer S, Nilsson LJ, Åhman M, Schneider C (2016) Decarbonising the energy intensive basic materials industry through electrification-implications for future EU electricity demand. Energy 115:1623-1631. https://doi.org/10.1016/j.energy.2016. 07.110

Lovio R, Mickwitz P, Heiskanen E (2011) Path dependence, path creation and creative destruction in the evolution of energy systems. In: Wüstenhagen R, Wuebker R (eds) The handbook of research on energy entrepreneurship. Edward Elgar Publishing, Cheltenham, pp 274-201

Luederitz C, Abson DJ, Audet R, Lang DJ (2017) Many pathways toward sustainability: not conflict but co-learning between transition narratives. Sustain Sci 12:393-407. https://doi.org/10.1007/ s11625-016-0414-0

Luthra S, Kumar S, Garg D, Haleem A (2015) Barriers to renewable/ sustainable energy technologies adoption: Indian perspective. Renew Sustain Energy Rev 41:762-776. https://doi.org/10.1016/j. rser.2014.08.077

Mani M, Varghese K, Ganesh LS (2005) Integrated model framework to simulate sustainability of human settlements. J Urban Plan Dev 
131:147-158. https://doi.org/10.1061/(ASCE)0733-9488(2005) $131: 3(147)$

Marsden T (2009) Mobilities, vulnerabilities and sustainabilities: exploring pathways from denial to sustainable rural development. Sociol Rural 49:113-131. https://doi.org/10.1111/j.1467-9523. 2009.00479.x

Masuda H (2014) Chihou Shoumetsu: Tokyo ikkyo kushuuchuu ga maneku jinkou kyuugen (vanishing regions). Chuko-shinsho

Matanle P, Sáez-Pérez L-A (2019) Searching for a depopulation dividend in the 21st century: perspectives from Japan, Spain and New Zealand. J JpnInst Lands Archit 83:1

Mattila TJ, Pakarinen S, Sokka L (2010) Quantifying the total environmental impacts of an industrial symbiosis - a comparison of process-, hybrid and input-output life cycle assessment. Environ SciTechnol 44:4309-4314. https://doi.org/10.1021/es902673m

Mayer H, Habersetzer A, Meili R (2016) Rural-urban linkages and sustainable regional development: the role of entrepreneurs in linking peripheries and centers. Sustainability 8:745. https://doi. org/10.3390/su8080745

Mebratu D (1998) Sustainability and sustainable development: Historical and conceptual review. Environ Impact Assess Rev 18:493520. https://doi.org/10.1016/S0195-9255(98)00019-5

MOEJ (Ministry of Environment of Japan) (2007) 21 seiki kankyo rikkoku senryaku [21st Century Environmental National Strategy]

MOEJ (Ministry of Environment of Japan) (2018) The basic environment plan

Molotch H (1993) The political economy of growth machines. J Urban Aff 15:29-53. https://doi.org/10.1111/j.1467-9906.1993.tb003 01.x

Mont O, Plepys A, Whalen K, Nußholz JLK (2017) Business model innovation for a circular economy: drivers and barriers for the Swedish industry - the voice of REES companies

Munang R, Thiaw I, Alverson K et al (2013) Climate change and ecosystem-based adaptation: a new pragmatic approach to buffering climate change impacts. CurrOpin Environ Sustain 5:67-71. https://doi.org/10.1016/j.cosust.2012.12.001

Munang R, Andrews J, Alverson K, Mebratu D (2014) Harnessing ecosystem-based adaptation to address the social dimensions of climate change. Environ Sci Policy Sustain Dev 56:18-24. https:// doi.org/10.1080/00139157.2014.861676

Nakamura K, Kitamura K (2018) Creating platforms for capacity building in rural communities: Noto Peninsula, Japan and Ifugao, the Philippines. In: Sato T, Chabay I, Helgeson J (eds) Transformations of social-ecological systems: studies in co-creating integrated knowledge toward sustainable futures. Springer, Singapore, pp 189-207

Ortiz-Moya F (2020) Green growth strategies in a shrinking city: Tackling urban revitalization through environmental justice in Kitakyushu City, Japan. J Urban Aff 42:312-332. https://doi.org/ 10.1080/07352166.2018.1448225

Pomponi F, Moncaster A (2017) Circular economy for the built environment: a research framework. J Clean Prod 143:710-718

Qiu Z, Bixia C (2016) Empowerment of an aging population and rural women farmers: a small business model-a Japanese case study. JORE 7:486-494. https://doi.org/10.5814/j.issn.1674-764x.2016. 06.009

Saito O (2017) Future science-policy agendas and partnerships for building a sustainable society in harmony with nature. Sustain Sci 12:895-899. https://doi.org/10.1007/s11625-017-0475-8

Saito O, Kamiyama C, Hashimoto S et al (2019) Co-design of nationalscale future scenarios in Japan to predict and assess natural capital and ecosystem services. Sustain Sci 14:5-21. https://doi.org/10. 1007/s11625-018-0587-9

Satterthwaite D, Tacoli C (2006) The role of small and intermediate urban centres in regional and rural development: assumptions and evidence. In: Tacoli C (ed) TheEarthscan reader in rural-urban linkages. Earthscan, London, pp 155-183

Shimada K, Tanaka Y, Gomi K, Matsuoka Y (2007) Developing a long-term local society design methodology towards a low-carbon economy: an application to Shiga Prefecture in Japan. Energy Policy 35:4688-4703. https://doi.org/10.1016/j.enpol.2007.03.025

Skea J, Nishioka S (2008) Policies and practices for a low-carbon society. Clim Policy 8:S5-S16. https://doi.org/10.3763/cpol.2008.0487

Sovacool BK (2009) The cultural barriers to renewable energy and energy efficiency in the United States. TechnolSoc 31:365-373. https://doi.org/10.1016/j.techsoc.2009.10.009

Steffen W, Richardson K, Rockström J et al (2015) Planetary boundaries: guiding human development on a changing planet. Science. https://doi.org/10.1126/science.1259855

Steinberg F (2014) Rural-urban linkages: an urban perspective. Working paper series

Suzu City (2010) Suzu-Shi Baiomasu Taun Kousou. Suzu

Suzu City (2018) Suzu-Shi SDGs Mirai Toshi Keikaku. Suzu

Suzu City (2020a) Suzu-Shi Jinkou Bijon (Kaichouban). Suzu City, Suzu

Suzu City (2020b) Dai 2-ki Suzu-shi machi hito shi-goto sōsei sōgō senryaku. Suzu City, Suzu

Tacoli C (1998) Rural-urban interactions: a guide to the literature. Environ Urban 10:147-166. https://doi.org/10.1177/0956247898 01000105

Tacoli C (2003) The links between urban and rural development. Environ Urban 15:3-12. https://doi.org/10.1177/095624780301500111

Takeuchi K (2010) Rebuilding the relationship between people and nature: the Satoyama Initiative. Ecol Res 25:891-897. https://doi. org/10.1007/s11284-010-0745-8

Takeuchi K, Yamada T (2018) SDGs o gugen-kasuru "chiikijunkankyōsei-ken" no kōsō: Dai 5-ji kankyōkihonkeikaku o yomitoku. Environ Manag 7:8-12

Takeuchi K, Elmqvist T, Hatakeyama M et al (2014) Using sustainability science to analyse social-ecological restoration in NE Japan after the great earthquake and tsunami of 2011. Sustain Sci 9:513-526. https://doi.org/10.1007/s11625-014-0257-5

Takeuchi K, Ichikawa K, Elmqvist T (2016) Satoyama landscape as social-ecological system: historical changes and future perspective. CurrOpin Environ Sustain 19:30-39. https://doi.org/10. 1016/j.cosust.2015.11.001

Takeuchi K, Fujino J, Ortiz-Moya F et al (2019) The circulating and ecological economy - regional and local CES: an IGES proposal. Institute for Global Environmental Strategies, Hayama

Tanaka R, Hashimoto S, Hoshino S, Shimizu N (2014) Explorative qualitative study on regional factors affecting subjective wellbeing of rural residents: interview survey with residents of Suzu, Ishikawa. J Assoc Rural Plan 33:299-304. https://doi.org/10.2750/ $\operatorname{arp} .33 .299$

Thapa K, Sukhwani V, Deshkar S et al (2020) Strengthening urbanrural resource flow through Regional Circular and Ecological Sphere (R-CES) approach in Nagpur India. Sustainability 12:8663. https://doi.org/10.3390/su12208663

UNDESA (2019) World urbanization prospects: the 2018 revision. United Nations, New York

UNEP (2011) Restoring the natural foundation to sustain a green economy: a century-long journey for ecosystem management. UNEP, New York

UN-HABITAT (2011) Cities and climate change: global report on human settlements 2011. United Nations Human Settlements Programme, Nairobi

Wachsmuth D (2012) Three ecologies: urban metabolism and the society-nature opposition. Sociol Q 53:506-523. https://doi.org/ 10.1111/j.1533-8525.2012.01247.x 
Walker G, Cass N (2007) Carbon reduction, 'the public' and renewable energy: engaging with socio-technical configurations. Area 39:458-469. https://doi.org/10.1111/j.1475-4762.2007.00772.x

Wamsler C (2015) Mainstreaming ecosystem-based adaptation: transformation toward sustainability in urban governance and planning. EcolSoc 20:30

Wijkman A, Skanberg K (2015) The circular economy and benefits for society. Club of Rome, Rome
Williams J (2019) Circular cities. Urban Stud 56:2746-2762. https:// doi.org/10.1177/0042098018806133

Woods M (2009) Rural geography: blurring boundaries and making connections. Prog Hum Geogr 33:849-858. https://doi.org/10. $1177 / 0309132508105001$

Publisher's Note Springer Nature remains neutral with regard to jurisdictional claims in published maps and institutional affiliations. 